|| ISSN(online): 2589-8698 || ISSN(print): 2589-868X ||

International Journal of Medical and Biomedical Studies

Available Online at www.ijmbs.info

NLM (National Library of Medicine ID: 101738825)

Index Copernicus Value 2019: 79.34

Original Research Article

Volume 5, Issue 4; April: 2021; Page No. 01-04

\title{
ROLE OF USG FINDINGS AS A PREDICTIVE MARKER IN THREATENED ABORTION
}

\section{Dr. Kamlesh Yadav ${ }^{1}$, Dr. Pragya Ojha ${ }^{2}$}

${ }^{I}$ Senior Professor, Department of Obst \& Gynae, Sardar Patel Medical College and Associated Group of Hospitals Bikaner, Rajasthan.

${ }^{2} 3^{\text {rd }}$ Year Post Graduate Resident, Department of Obst \& Gynae, Sardar Patel Medical College and Associated Group of Hospitals Bikaner, Rajasthan.

Article Info: Received 08 February 2021; Accepted 28 March 2021

DOI: https://doi.org/10.32553/ijmbs.v5i4.1853

Corresponding author: Dr. Pragya Ojha

Conflict of interest: No conflict of interest.

\section{Abstract}

Background: The Centers for disease control and prevention, and the World Health Organization all define abortion as pregnancy termination before 20 week gestation or with fetus born weighing $<500 \mathrm{~g}^{[1]}$. Early pregnancy USG parameters: fetal crown-rump length (CRL), the presence/absence of sub-chorionic hematoma and Fetal Heart Rate (FHR) are good predictors of outcome.

Material and Methods: The study was conducted in the Department of Obstetrics and Gynaecology, S.P. Medical College Bikaner\& associated Group of Hospital, Bikaner, Rajasthan. This is a hospital based prospective comparative study. The study group comprise of pregnant females attending Obstetrics and Gynaecology OPD. A total of 200 pregnant women are examined in this study. We divided these patients into 2 groups i.e group A and group B. Group A consists of 100 pregnant females with threatened abortion and group B with 100 normal pregnant female.

Results: FHR at $115 \mathrm{bpm}$ is $76.32 \%$ sensitive, $90.32 \%$ specific in predicting abortion with $82.86 \%$ positive predictive value and $86.15 \%$ negative predictive value. While CRL at $11 \mathrm{~mm}$ is $50 \%$ sensitive, $69.35 \%$ specific in predicting abortion with $55 \%$ positive predictive value and $69.35 \%$ negative predictive value.

Conclusion: FHR is best predictive marker followed by presence or absence of sub-chorionic hematoma and CRL in threatened abortion which results in loss of pregnancy.

Keywords: Pregnancy, Abortion, Threatened, USG

\section{Introduction}

The Centers for disease control and prevention, and the World Health Organization all define abortion as pregnancy termination before 20 weeks gestation or with fetus born weighing $<500 \mathrm{~g}^{[1]}$. More than 80 percent of abortions occur in the first 12 weeks of pregnancy and at least half result from chromosomal anomalies. After the first trimester, both the abortion rate and the incidence of chromosomal anomalies decrease. ${ }^{2}$ Abortion may be spontaneous or induced. Threatened abortion is a type of spontaneous abortion

The definition of threatened abortion by WHO is, pregnancy related bloody vaginal discharge or frank bleeding during its first half of pregnancy without cervical dilatation. ${ }^{3}$ It is accounted for to happen in around one-fifth of pregnancies. ${ }^{4}$

Threatened abortion progress to pregnancy loss in about 50 percent cases. Additionally, first trimester bleeding assumes a role in the occurrence of late pregnancy complication..$^{5-8}$. Hence by preventing and managing threatened abortion complications can be avoided.

Numerous sonographic criteria have been studied to predict the outcome of threatened abortion. ${ }^{9}$
Various sonographic signs have been described to predict pregnancy outcome. Here signs included are gestational sac not corresponding to gestational age, or irregularly shaped gestational sac, a low implantation site, a large or irregular yolk sac, a weak decidual reaction, and slow embryonic heart rate. ${ }^{10}$

Early pregnancy markers in patients with threatened abortion including the size of gestational sac, size and shape of yolk sac, fetal crown-rump length (CRL), the presence/absence of sub-chorionic hematoma and Fetal Heart Rate (FHR) are good predictors of outcome.

\section{Material and Methods}

Study Population: The study was conduct in the Department of Obstetrics and Gynaecology, S.P.Medical College Bikaner\& associated Group of Hospital, Bikaner, Rajasthan from $1^{\text {st }}$ September 2019 to $31^{\text {st }}$ August 2020 This is a hospital based prospective comparative study. The study group comprise of pregnant females attending Obstetrics and Gynaecology OPD. A total of 200 pregnant women are examined in this study. We divided these patients into 2 groups i.e group A and group B. Group A consists of 100 pregnant female with threatened abortion and group B with 100 normal pregnant female. 
Inclusion criteria: 1. Patient who presented with complain of vaginal bleeding, closed and uneffaced cervix and/or abdominal pain at 6-12 weeks of gestational age.

2. The pregnancy should be confirmed by a visible gestational sac of a live embryo, verified by cardiac activity on a real time ultrasound and gestational age was calculated by their last menstrual period, in both groups.

3. Age of women ( 18 to 40 years).

Exclusion criteria: 1. Other abortions (incomplete or missed abortion)

2. Molar pregnancy.

3. Ectopic pregnancy.

4. Women not willing to participate in the study are excluded.

Data collection: After careful and thorough history, physical, and sonographic examination to confirm gestational age, fetal viability, intrauterine single gestation and after full filling the inclusion criteria and after taking informed consent, the participants were allocated in two groups.

Data Analysis: To collect required information from eligible patients a pre-structured pre-tested Performa was used. For data analysis Microsoft excel and statistical software SPSS will be used and data were analyzed with the help of frequencies, figures, proportions, measures of central tendency, appropriate statistical test.

\section{Result}

Table 1: Distribution of patients in both groups.

\begin{tabular}{|l|l|l|l|l|}
\hline Pregnancy & \multicolumn{3}{|l|}{ Group A } & Group B \\
\cline { 2 - 5 } & No. of Patients & Percentage & No. of Patients & Percentage \\
\hline Continued & 62 & 62 & 82 & 82 \\
\hline Aborted & 38 & 38 & 18 & 18 \\
\hline Total & 100 & 100 & 100 & 100 \\
\hline
\end{tabular}

Our study population is classified in 2 groups i.e. group A is case group and group B is control group. Out of 100 patients of group A $62 \%$ patients continued pregnancy and $38 \%$ patients aborted and for group B $82 \%$ patients continued pregnancy and $18 \%$ aborted.

In Study, majority $73 \%$ and $74 \%$ patients of group A and B respectively are lower class category. The p-value is 0.87 . The result is non-significant as p-value is $>0.05$.

In our study, most of the patients $56 \%$ were of age $25-30$ years in group A and in group B $52 \%$ patients were $<25$ years of age. Mean age of group A is $24.95 \pm 3.40$ years and of group B is $24.62 \pm 3.28$ years. p-value 0.87

In our study, majority $39 \%$ and $42 \%$ patients are of nullipara, $29 \%$ and $28 \%$ patients are of 1 parity, $22 \%$ and $22 \%$ of patients are of 2 parity respectively for group A and group B. The result is non-significant.
Majority 48\% patients are of gestational age 8-10 weeks for both groups. Mean gestation age for group $\mathrm{A}$ is $8.81 \pm 1.74$ weeks and for group B is $8.61 \pm 1.78$ weeks. The $\mathrm{p}$-value is 0.42 . The result is non-significant.

Table 2: Distribution of patients according to Subchorionic Haematoma

\begin{tabular}{|c|c|c|c|c|c|}
\hline \multirow{2}{*}{$\begin{array}{l}\text { Subchorionic } \\
\text { Haematoma }\end{array}$} & \multicolumn{2}{|l|}{ Group A } & \multicolumn{2}{|l|}{ Group B } & \multirow[t]{2}{*}{ P VALUE } \\
\hline & $\begin{array}{l}\text { No. of } \\
\text { Patients }\end{array}$ & $\begin{array}{l}\text { Percentage } \\
(\%)\end{array}$ & $\begin{array}{l}\text { No. of } \\
\text { Patients }\end{array}$ & $\begin{array}{l}\text { Percentage } \\
(\%)\end{array}$ & \\
\hline Absent & 85 & 85 & 96 & 96 & 0.008 \\
\hline Present & 15 & 15 & 4 & 4 & 0.008 \\
\hline Total & 100 & 100 & 100 & 100 & \\
\hline
\end{tabular}

In our study, majority $85 \%$ in group A and $96 \%$ patients in group B had no subchorionic haematoma. $15 \%$ in group A and $4 \%$ in group B had subchorionic haematoma. The pvalue is 0.008 , the result is significant.

Table 3: Distribution of patients according to ultrasound parameters in group A.

\begin{tabular}{|l|l|l|l|l|l|}
\hline \multirow{3}{*}{ Parameter } & \multicolumn{3}{|l|}{ Group A } & \multirow{2}{*}{ p value } \\
\cline { 2 - 5 } & Aborted & \multicolumn{2}{|l|}{ Continued } & \\
\cline { 2 - 5 } & Mean & SD & Mean & SD & \\
\hline CRL (mm) & 19.31 & 13.22 & 22.17 & 15.49 & 0.16 \\
\hline FHR (per minute) & 108.89 & 14.46 & 128.32 & 13.51 & $<0.0001$ \\
\hline
\end{tabular}

Table shows, Mean CRL is 19.31 ( $\mathrm{SD}=13.22)$ for group A (Aborted) and 22.17 ( $\mathrm{SD}=15.49)$ for Group A (continued). Mean FHR for group A (Aborted) is $108.89(\mathrm{SD}=14.46)$ per minute and for Group A (continued) is 128.32 ( $\mathrm{SD}=13.51)$ per minute. The $\mathrm{p}$ value for CRL is 0.16 and for FHR is $<0.0001$.

Table 4: Distribution of patients according to ultrasound parameters in group B.

\begin{tabular}{|l|l|l|l|l|l|}
\hline \multirow{3}{*}{ Parameter } & \multicolumn{3}{|l|}{ Group B } & \multirow{2}{*}{ p value } \\
\cline { 2 - 5 } & \multicolumn{2}{|l|}{ Aborted } & \multicolumn{2}{l|}{ Continued } & \\
\cline { 2 - 5 } & Mean & SD & Mean & SD & \\
\hline CRL (mm) & 16.44 & 11.37 & 23 & 15.1 & 0.0006 \\
\hline FHR (per minute) & 105.55 & 5.11 & 127.12 & 14.79 & $<0.0001$ \\
\hline
\end{tabular}

According to table, Mean CRL is 16.44 ( $\mathrm{SD}=11.37)$ for group B (Aborted) and $23(\mathrm{SD}=15.1)$ for Group B (continued). Mean FHR for group B (Aborted) is 105.55 $(\mathrm{SD}=5.11)$ per minute and for Group B (continued) is $127.12(\mathrm{SD}=14.79)$ per minute. The $\mathrm{p}$ value for $\mathrm{CRL}$ is 0.0006 and for FHR is $<0.0001$.

Table 5: ROC analysis for FHR and CRL for predicting abortion.

\begin{tabular}{|l|l|l|l|l|}
\hline PARAMTER & AUC & P-VALUE & CI 95\% & CUTOFF \\
\hline CRL & 0.606 & 0.076 & $0.485-0.727$ & 11 \\
\hline FHR & 0.846 & $<0.001$ & $0.755-0.937$ & 115 \\
\hline
\end{tabular}

ROC curves of FHR and CRL in predicting abortion were plotted. The AUC for FHR and CRL 0.846 (95\% CI $0.755-$ 
0.937 ) and 0.606 (95\% CI 0.755-0.937), respectively. ROC curve gives cut off level of FHR 115bpm and of CRL 11 $\mathrm{mm}$ in predicting the risk of abortion

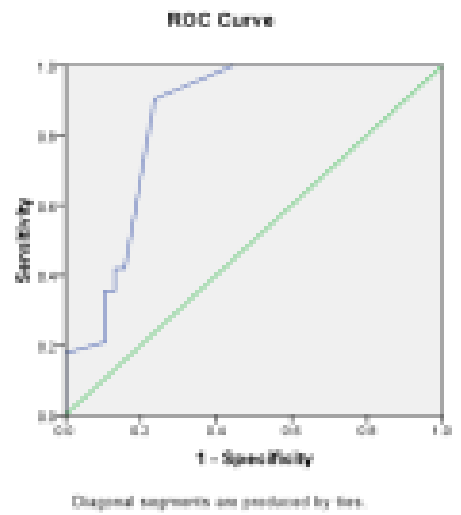

Figure 5a: ROC analysis for FHR for predicting abortion

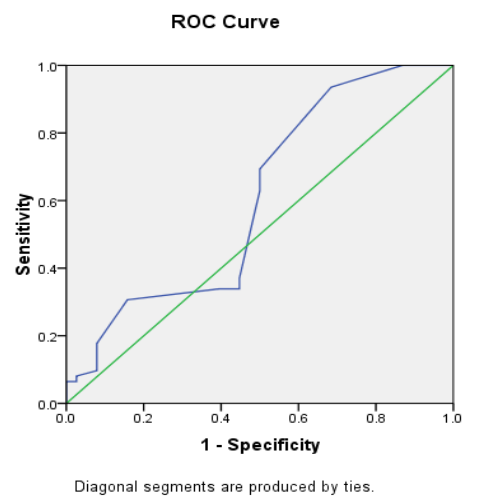

Figure 5b: ROC analysis for CRL for predicting abortion

Table 6: sensitivity, specificity, PPV, NPV of FHR for abortion.

\begin{tabular}{|l|l|l|}
\hline & Aborted & Continued \\
\hline FHR $(<115)$ & 29 & 6 \\
\hline FHR $(\geq 115)$ & 9 & 56 \\
\hline Sensitivity & $76.32 \%$ & \\
\hline Specificity & $90.32 \%$ & \\
\hline PPV & $82.86 \%$ & \\
\hline NPV & $86.15 \%$ & \\
\hline Accuracy & $85 \%$ & \\
\hline
\end{tabular}

In this study we found that FHR was $76.32 \%$ sensitive, 90.32\% specific in predicting abortion with $82.86 \%$ positive predictive value and $86.15 \%$ negative predictive value.

Table 7: Sensitivity, Specificity, PPV, NPV of CRL for abortion.

\begin{tabular}{|l|l|l|}
\hline & Aborted & Continued \\
\hline CRL $(<11)$ & 19 & 19 \\
\hline CRL $(\geq 11)$ & 19 & 43 \\
\hline Sensitivity & $50 \%$ & \\
\hline Specificity & $69.35 \%$ & \\
\hline PPV & $50 \%$ & \\
\hline NPV & $69.35 \%$ & \\
\hline Accuracy & $62 \%$ & \\
\hline
\end{tabular}

CRL was $50 \%$ sensitive, $69.35 \%$ specific in predicting abortion with $50 \%$ positive predictive value and $69.35 \%$ negative predictive value.

\section{Discussion}

The first trimester vaginal bleeding is common obstetrical complication, occuring in $25 \%$ of all pregnancies. Threatened miscarriage defined as vaginal bleeding between 24 weeks in closed Cervical os.

According to our study mean age of group A was $24.95 \pm 3.04$ years and in group B was $24.62 \pm 3.28$ years. Pvalue was 0.48 . Most of the patients $66 \%$ and $68 \%$ were illiterate in group A and group B respectively. Majority $65 \%$ and $70 \%$ patients were from rural area in group A and group B respectively. $73 \%$ and $74 \%$ patients of group A and group B respectively were lower class category. In our study $39 \%$ and $42 \%$ patients were nulliparous, $29 \%$ and $28 \%$ were para $1,22 \%$ and $22 \%$ of patients are para 2 respectively for group A and group B. In our study mean gestational age of group A is $8.81 \pm 1.74$ weeks and group B is $8.61 \pm 1.78$ weeks. Mean haemoglobin for group A was $10.04 \pm 1.56 \mathrm{gm} / \mathrm{dl}$ and for group B was $9.8 \pm 1.22 \mathrm{mg} / \mathrm{dl}$. Mean RBS for group A was 119 and for group B was 117.7. All above demographic and laboratory parameters were insignificant.

We considered ultrasound parameters SCH, CRL and FHR. Majority $85 \%$ in group A and $96 \%$ patients in group B have no subchorionic haematoma. $15 \%$ in group $\mathrm{A}$ and $4 \%$ in group B have subchorionic haematoma. The p-value was 0.008 . The result was significant.

Mean CRL was 19.31(SD=13.22) for group A (Aborted) and 22.17 ( $\mathrm{SD}=15.49$ ) for Group A (continued). Mean CRL was $16.44(\mathrm{SD}=11.37)$ for group $\mathrm{B}$ (Aborted) and 23 $(S D=15.1)$ for Group B (continued). The $p$ value for CRL in group A 0.16 and in group B was 0.0006 .

Mean FHR for group A (Aborted) 108.89 (SD=14.46) per minute and for Group A (continued) was 128.32 ( $\mathrm{SD}=13.51$ ) per minute. Mean FHR for Group B (Aborted) was $105.55(\mathrm{SD}=5.11)$ per minute and for Group $\mathrm{B}$ (continued) was $127.12(\mathrm{SD}=14.79)$ per minute. The $\mathrm{p}$ value for FHR in both group A and group B were $<0.0001$. The result was significant.

The AUC for FHR and CRL was 0.846 (95\% CI $0.755-$ 0.937 ) and 0.606 (95\% CI 0.755-0.937), respectively. According to our study, CRL is 50\% sensitive, $69.35 \%$ specific in predicting abortion with $50 \%$ positive predictive value and $69.35 \%$ negative predictive value. According to this study FHR is $76.32 \%$ sensitive, $90.32 \%$ specific in predicting abortion with $82.86 \%$ positive predictive value and $86.15 \%$ negative predictive value. These finding are consistent with study by Oun A E M et al ${ }^{11}$ and Maged ${ }^{12}$. However, Maged ${ }^{12}$ and Al Mohamady et al ${ }^{13}$. (2016) reported that, there was no significant difference between groups as regard to crown rump length, and these results are confirmed in the present work. Regarding fetal heart rate, results of the present study was in agreement with Doubilet and Benson's ${ }^{14}$ and Tannirandorn et al findings. ${ }^{15}$ 


\section{Conclusion:}

USG is inexpensive, easily available, fast, non-invasive predictors of threatened abortion which may results in loss of pregnancy. FHR is best predictive marker followed by presence or absence of sub-chorionic hematoma and CRL in threatened abortion which results in loss of pregnancy.

\section{References:}

1. "Pregnancy: Condition Information". Eunice Kennedy Shriver National Institute of Child Health and Human Development. 19 December 2013. Archived from the original on 19 March 2015. Retrieved 14 March 2015.

2. Rubio C, Simón C, Vidal F, Rodrigo L, Pehlivan T, Remohí J, et al. Chromosomal abnormalities and embryo development in recurrent miscarriage couples. Hum Reprod. 2003; 18(1): 182-188.

3. Redinger A, Nguyen H. StatPearls [Internet]. StatPearls Publishing; Treasure Island (FL): Jun 30,2020. Incomplete Abortions.

4. Saraswat L, Bhattacharya S, Maheshwari A. Maternal and perinatal outcome in women with threatened miscarriage in the first trimester: a systematic review. BJOG. 2010; 117:245-257.

5. Arafa M, Abdel-Fattah M, Zeid HA. Outcomes of pregnancies complicated by early vaginal bleeding. East Mediterr Health J 2000; 6: 457-464.

6. Yang J, Hartmann KE, Savitz DA, Herring AH, Dole $\mathrm{N}$, et al. Vaginal bleeding during pregnancy and preterm birth. Am J Epidemiol 2004; 160: 118-125.

7. Elson J, Salim R, Tailor A, Banerjee S, Zosmer N, et al. Prediction of early pregnancy viability in the absence of an ultrasonically detectable embryo. Ultrasound obstet gynecol 2003; 21: 57-61.
8. Nyberg DA, Mack LA, Harvey D, Wang K Value of the yolk sac in evaluating early pregnancies. J ultrasound med 1988; 7: 129-135.

9. Altay MM, Yaz H, Haberal A. The assessment of the gestational sac diameter, crown-rump length, progesterone and fetal heart rate measurements at the 10th gestational week to predict the spontaneous abortion risk. J Obstet Gynecol Res 2009; 35: 287-292

10. Tan S, Tangal NG, Kanat-Pektas M, Özcan AŞ, Keskin HL. Abnormal sonographic appearances of the yolk sac: which can be associated with adverse perinatal outcome? Med Ultrasonography. 2014; 16: 15-20.

11. Oun A E M, Ibrahem E M, Elaziz M R A. Role of Both Serum CA125 and Ultrasound in Prediction of Pregnancy Outcome in First trimester Threatened Miscarriage. International Journal of Life Sciences.2018;7(2):79-84.

12. Maged A M, Mostafa W A. Biochemical and ultrasonographic predictors of outcome in threatened abortion. Middle East Fertil Soc J (2013),

13. Mohamady M A, Fattah G A, Elkattan E, Byoumy R, Hamed D A. Correlation of Serum CA-125 and Progesterone Levels with Ultrasound Markers in The Prediction of Pregnancy Outcome in Threatened Miscarriage. Int J Fertil Steril 2016; 9(4).

14. Doubilet PM, Benson CB. Outcome of first-trimester pregnancies with slow embryonic heart rate at 6-7 weeks gestation and normal heart rate by 8 weeks at US. Radiology. 2011; 236(2): 643-646.

15. Tannirandorn $\mathrm{Y}$, Sangsawang S, Manotaya S, Uerpairojkit B , Samritpradit P, Charoenvidhya D. Fetal loss in threatened abortion after embryonic/fetal heart activity. Int J Gynaecol Obstet. 2003; 81: 263 266. 